\title{
The Place Premium: Bounding the Price Equivalent of Migration Barriers
}

Michael A. Clemens, Center for Global Development and IZA

Claudio Montenegro, World Bank, University of Chile Dept. of Economics, and German Development Institute (DIE)

Lant Pritchett, Harvard Kennedy School and CGD

June 2018

Abstract: Large international differences in the price of labor can be sustained by differences between workers, or by natural and policy barriers to worker mobility. We use migrant selection theory and evidence to place lower bounds on the ad valorem equivalent of labor mobility barriers to the United States, with unique nationally-representative microdata on both U.S. immigrant workers and workers in their 42 home countries. The average price equivalent of migration barriers in this setting, for low-skill males, is greater than $\$ 13,700$ per worker per year. Natural and policy barriers may each create annual global losses of trillions of dollars.

JEL Codes F22, J61, O15. We thank Indermit S. Gill and team at the World Development Report for data, and Samuel Bazzi and Paolo Abarcar for research assistance, as well as Randall Akee, Christopher Blattman, Patricia Cortés, William Easterly, David Ellwood, Deon Filmer, Eric Gould, Rema Hanna, Eric Hanushek, Ricardo Hausmann, Chad Jones, Lawrence Katz, John Kennan, Amit Khandelwal, Asim Khwaja, Robert Lawrence, David Lindauer, David McKenzie, Dani Rodrik, Mark Rosenzweig, Justin Sandefur, T. N. Srinivasan, anonymous referees, and seminar participants at the AEA meetings, Yale, Harvard, Brookings, U. Maryland, and LACEA. For support we thank the MacArthur Foundation, AusAID, and the Open Philanthropy Foundation. All view and any errors are the authors' alone. 


\section{Introduction}

Economists often study the costs of frictions in international commerce by estimating their ad valorem equivalent. Such estimates are made for frictions that include trade quotas (e.g. Anderson and van Wincoop 2004), transportation costs (e.g. Hummels 2007), and capital controls (Edwards et al. 1999). But there are no systematic estimates of the price equivalent of barriers to the international movement of labor. Both the simple "Harberger triangle" intuition that the welfare losses rise with the square of the price distortion and calibrated models of the world economy suggest that if the price equivalent of migration barriers is high, the annual global costs are trillions of dollars. ${ }^{1}$

We use a unique collection of data sets on individuals' wages from 42 developing countries and the United States to place lower bounds on the price equivalent of barriers to labor mobility into the U.S. market. We estimate the real (Purchasing Power Parity) wage gaps between immigrants in the United States and their observably-equivalent national counterparts in the 42 home labor markets. We then use theory and evidence on migrant self-selection to bound the real wage gap for fully equivalent workers - adjusted for both observable and unobservable characteristics. We call this wage gap a 'place premium' because it does not arise from portable individual traits. We then use these bounds on the place premium to discuss what fraction of this price wedge might plausibly be attributed to natural barriers and what fraction to policy barriers.

\footnotetext{
${ }^{1}$ Surveyed by Clemens (2011), and recently investigated by Benhabib and Jovanovic (2012); Kennan (2013); di Giovanni et al. (2015).
} 
Our focus is on prime-age, low-skill males educated abroad (35-39 years old, 9-12 years of education acquired in the home country), though we present estimates for other demographic categories as well. We calculate lower bounds on the ratio of real wages in the U.S. to real wages of an identical worker in each home country. This lower bound varies greatly across countries, from a high of 16.4 for Yemen to a low of 1.7 for Morocco. Weighted by the working-age (15-49) population of the home countries, the average lower bound on this wage ratio is 5.65. For the median country the lower bound is 3.95 , and for the $80^{\text {th }}$ percentile country the lower bound is 6.14. The working-age population weighted average of the lower bound on the absolute wage gain is $\mathrm{PPP} \$ 13,710 /$ year across 1.5 billion working-age people from the 42 countries. The lower bound absolute gain for workers from the median country is $\operatorname{PPP} \$ 13,600$, and for the $80^{\text {th }}$ percentile country it is $\operatorname{PPP} \$ 15,600$.

We cannot separately estimate for each country the relative contributions of natural and policy barriers. That said, we note that spatially integrated labor markets in the absence of policy barriers rarely sustain real wage ratios above 1.5 - even in the presence of important cultural and geographic barriers. This suggests a plausible prior that policy barriers to labor mobility account for at least as much of the observed gap in wages of fully equivalent workers than do natural barriers to movement, such as psychic costs or transportation costs.

The empirical contribution of this work is the first country-specific bounds on the price equivalent of migration barriers using data on nationally-representative samples of individual workers from the same country working on both sides of the border. $^{2}$ The methodological contribution is to propose new measures of selection bias

${ }^{2}$ Ashenfelter (2012) measures large real wage gaps between several countries 
in these estimates - derived from the theory of migrant self-selection, and predicting patterns in the estimates by country of origin, by skill group, and by labor-market outcomes in the destination country.

\section{Wage ratios for observably equivalent workers}

Our calculations analogous to ad valorem measures of trade barriers. We seek to place bounds on similar price ratios for labor - wage ratios - as ad valorem measures of natural and policy barriers to labor mobility.

\subsection{Defining the wage ratios}

$R_{u}$ is the unconditional ratio of migrants' wages in the United States to wages in the home country, without adjustment for observable or unobservable differences between average migrants and average non-migrants. $R_{c}$ is the ratio conditional on observable inherent differences like age and education. Finally, $R$ accounts for all inherent differences, both observable and unobservable. That is, ratio $R$ measures the real wage gain that the same person could expect in the U.S. relative to the home country.

within one low-skill occupation: fast-food workers. Multiple studies use microdata on migrants to find that country of residence is at least as important a determinant of worker productivity as inherent characteristics, but do not estimate international labor-price wedges separately by country (Hendricks 2002; Milanovic 2015; Hendricks and Schoellman 2018). 
Formally, suppose that a worker born and educated in a foreign country would earn $w_{0}$ in that home country and earn $w_{\mathrm{US}}$ in the United States, and that $w_{0}$ and $w_{\mathrm{US}}$ are are determined by:

$$
\begin{aligned}
\ln w_{0}=\left(\mu_{0}+\gamma_{0} s\right)+\widetilde{\gamma}_{0} \widetilde{s} & \equiv \mu_{0}^{\prime}(s)+\widetilde{\gamma}_{0} \widetilde{s} \\
\ln w_{\mathrm{US}}=\left(\mu_{\mathrm{US}}+\gamma_{\mathrm{US}} s\right)+\widetilde{\gamma}_{\mathrm{US}} \widetilde{s} & \equiv \mu_{\mathrm{US}}^{\prime}(s)+\widetilde{\gamma}_{\mathrm{US}} \widetilde{s}
\end{aligned}
$$

where $s \geqslant 0$ is observed skill, which has return $\gamma_{0}$ abroad and $\gamma_{\mathrm{US}}$ in the United States; $\widetilde{s} \sim N(0, \sigma)$ is unobserved skill, which has return $\widetilde{\gamma}_{0}$ abroad and $\widetilde{\gamma}_{\text {US }}$ in the United States. Fundamental differences in worker productivity between the two countries are captured by $\mu_{\mathrm{US}}$ and $\mu_{0}$.

The three wage ratios of interest can then be defined as

$$
\begin{array}{r}
\ln R_{u} \equiv \mu_{\mathrm{US}}-\mu_{0}+\left(\gamma_{\mathrm{US}} E_{\mathrm{US}}[s]-\gamma_{0} E_{0}[s]\right)+\left(\widetilde{\gamma}_{\mathrm{US}} E_{\mathrm{US}}[\widetilde{s}]-\widetilde{\gamma}_{0} E_{0}[\widetilde{s}]\right) \\
\ln R_{c}(s) \equiv \mu_{\mathrm{US}}-\mu_{0}+\left(\gamma_{\mathrm{US}}-\gamma_{0}\right) E_{\mathrm{US}}[s]+\left(\widetilde{\gamma}_{\mathrm{US}} E_{\mathrm{US}}[\widetilde{s}]-\widetilde{\gamma}_{0} E_{0}[\widetilde{s}]\right) \\
\ln R(s, \widetilde{s}) \equiv \mu_{\mathrm{US}}-\mu_{0}+\left(\gamma_{\mathrm{US}}-\gamma_{0}\right) E_{\mathrm{US}}[s]+\left(\widetilde{\gamma}_{\mathrm{US}}-\widetilde{\gamma}_{0}\right) E_{\mathrm{US}}[\widetilde{s}] .
\end{array}
$$

where $E_{0}$ and $E_{\mathrm{US}}$ denote expectations - across residents of the home country and residents of the United States, respectively - for people born in the home country. The ratio $R$ is the 'place premium', the real wage premium that a worker earns by working in the United States rather than their home country.

The ratios $R_{u}, R_{c}$, and $R$ compactly summarize migrant selection on observed and unobserved wage determinants. $R_{u} / R_{c}>1$ if and only if there is positive selection of migrants on observables, since $\ln \left(R / R_{c}\right)=\gamma_{0}\left(E_{\mathrm{US}}[s]-E_{0}[s]\right)>0 \Leftrightarrow E_{\mathrm{US}}[s]>$ 
$E_{0}[s]$. Likewise, $R_{c} / R>1$ if and only if there is positive selection of migrants on unobservables, since $\ln \left(R_{c} / R\right)=\widetilde{\gamma}_{0}\left(E_{\mathrm{US}}[\tilde{s}]-E_{0}[\widetilde{s}]\right)>0 \Leftrightarrow E_{\mathrm{US}}[\tilde{s}]>E_{0}[\tilde{s}]$.

To begin to estimate these ratios, for each country of birth we run a separate regression for each country (other than the U.S.) where the sample includes all workers born that country, whether they reside in the home country or the U.S.:

$\ln w=\alpha+\beta I_{\mathrm{US}}+\boldsymbol{I}_{\text {edu }}^{\prime}\left(\boldsymbol{\eta}_{\text {edu }}+\boldsymbol{\zeta}_{\text {edu }} I_{\mathrm{US}}\right)+\boldsymbol{I}_{\text {age }}^{\prime}\left(\boldsymbol{\eta}_{\text {age }}+\boldsymbol{\zeta}_{\text {age }} I_{\mathrm{US}}\right)+I_{\text {fem }}\left(\eta_{\text {fem }}+\zeta_{\text {fem }} I_{\mathrm{US}}\right)+\varepsilon$,

where $w$ is the monthly wage in U.S. dollars, and $I_{\mathrm{US}}$ is equal to one if the person lives in the United States, zero otherwise. $\boldsymbol{I}_{\text {edu }}$ and $\boldsymbol{I}_{\text {age }}$ are vectors of indicator variables for different groupings of years-of-education and quinquennial age, and $I_{\text {fem }}$ is an indicator for female. ${ }^{3}$ To be estimated are the parameters $\alpha, \beta, \eta_{\mathrm{fem}}$, and $\zeta_{\text {fem }}$, and the parameter vectors $\boldsymbol{\eta}_{\text {edu }}, \boldsymbol{\zeta}_{\text {edu }}, \boldsymbol{\eta}_{\text {age }}, \boldsymbol{\zeta}_{\text {age }}$, while $\varepsilon$ is an error term. This specification allows all observable traits to have different returns in the two countries, and assumes less about functional form than a model linear in traits. The key parameters are $\beta$ and the vectors $\boldsymbol{\zeta}$.

${ }^{3}$ The six education categories are 1) no schooling, 2) 1-4 years of schooling, 3) 5-8 years, 4) 9-12 years, 5) 13-16 years, and 6) 17-28 years. The ten age categories are 1) 15-19, 2) 20-24, 3) 25-29, 4) 30-34, 5) 35-39, 6) 40-44, 7) 45-49, 8) 50-54, 9) 55-59, 10) 60-65 (intentionally includes 65). The regressions also include dummy variables for the periodicity of wage reported (daily, weekly, etc.), suppressed here for clarity, with monthly as the base group. 


\subsection{Results}

We use a unique standardized collection of individual level data sets on wage-earners compiled by the World Bank, combined with the US Census Public Use Microdata Sample (PUMS) five percent file. ${ }^{4}$ The unified database describes 2,015,411 individual wage-earners, age 15 to 65, residing in 43 countries close to the year 2000 . This comprises 891,158 individuals residing in 42 developing countries, 623,934 individuals born in those same 42 developing countries but residing in the US, and 500,319 individuals born in the US and residing in the US. Wages are measured in 1999 US dollars at Purchasing Power Parity (PPP).

Table 1 presents estimates of $R_{u}$ and $R_{c}$ where wages are measured in Purchasing Power Parity (PPP) U.S. dollars. The first column shows $\hat{\beta}$ without any controls for education, age, and sex; the second column shows $\hat{\beta}+\hat{\zeta}_{\text {edu }}^{9-12}+\hat{\zeta}_{\text {age }}^{35-39}$ with controls included. ${ }^{5}$ The third column repeats the regressions with controls, but drops all

${ }^{4}$ Details of the database and all sources are given in the Appendix.

${ }^{5}$ The difference between the first and second column of results matches several results in the literature. The fact that the wage ratio falls for most countries when basic observable controls are added implies positive selection of migrants on observable determinants of earnings, in agreement with e.g. Brücker and Defoort (2009). The small change in the coefficient for Mexico when controls are added is compatible with previous findings of approximately neutral selection on observables for Mexico-U.S. migrants (Chiquiar and Hanson 2005), and the fact that the coefficient does fall slightly is compatible with findings of modest negative selection on basic observables (e.g. Fernández-Huertas 2011; Ambrosini et al. 2015). The ratio likewise 
U.S.-resident workers who were less than 20 years old when they arrived in the country. This eliminates most workers who received U.S. education, since domestic education and foreign education can have markedly different returns (e.g. Friedberg 2000). These last results are converted to the wage ratio $\hat{R}_{c}$ for the final column, and countries are sorted in decreasing values of this ratio.

The estimated wage ratios are very large. For the working-age population weighted average country of birth, $R_{c}=6.84$ while for the median country of birth, $R_{c}=$ 4.5 (five of the six largest countries in our sample (India, Indonesia, Bangladesh, Pakistan, Nigeria) have estimates above the median). These ratios represent the difference in purchasing power-adjusted wages between immigrants to the U.S. who received their education in the home country and observably equivalent workers in their country of origin-35-39 year-old male workers with 9-12 years of education who were born and educated in that home country.

The ratios are quite precisely estimated. For the ratios $R_{c}$, the $t$-statistic is above 10 in 38 out of 42 countries. Standard errors on $\hat{R}_{c}$ are bootstrapped with 500 draws to avoid the retransformation problem. The Appendix presents robustness checks for other ages, recently-arrived workers, and males only, and discusses the potential for reporting bias. All of these PPP-dollar wage ratios presume that wages are spent at U.S. prices, and are thus a conservative estimate of the gain to the extent that migrants remit a portion of wages to their (lower-price) home country. ${ }^{6}$

rises slightly between columns 1 and 2 for Nicaragua, as in Barham and Boucher's (1998) finding of negative selection.

${ }^{6}$ The Appendix presents a reestimate of Table 1 using official exchange rate 


\section{Bounding selection bias}

The principal objection to the use of $R_{c}$ to estimate the wage of equivalent labor in two different labor markets is that migrants are self-selected. For U.S. migrants negatively selected on unobserved determinants of earnings, such as Mexicans (e.g. Fernández-Huertas 2011), the estimates $R_{c}$ form a lower bound on the wage ratio for fully equivalent workers $R$. Under positive selection, $R_{c}$ can overstate $R$.

The rich microdata we use allow informative bounds on the bias from such selfselection, in three ways. The first uses coefficent stability tests to bound the bias, comparing the results to existing empirical estimates of selection on unobservables. The second is to derive tests for selection bias under Roy (1951) selection. The third tests predictions about positive selection arising from capital constraints.

\subsection{Lower bounds from coefficient stability}

The first approach is to estimate the degree of bias that would arise from different degrees of selection on unobservables, and compares this to selection estimates from the literature. Altonji et al. (2005) propose a method for bounding treatment effects under unobserved self-selection into treatment. They suggest that in many empirical settings the degree of selection on unobservables can be bounded from above by the degree of selection on observables. In rough terms, this is because if the included (observed) covariates were chosen at random from the set of possible (observed or

dollars. By that measure, $R_{c}$ takes the value 18.9 in the average country of birth, and 13.9 in the median country of birth. 
unobserved) covariates, then the degree of selection on observables would equal the degree of selection on unobservables. Researchers typically do not choose included covariates at random but specifically to reduce bias guided by theory, thus degree of selection explained by deliberately-chosen covariates must exceed the degree explained by omitted covariates. This suggests an avenue for bounding the degree of migrant selection on unobserved determinants of earnings, given that variables like education, age, and gender are chosen not at random but specifically to reduce selection bias: all are known to be first-order determinants of both earnings and migration.

Recently, Oster (2018) observes that this method may not be sufficiently conservative, and extends it. She shows that plausible bounds on selection must take account of the fraction of covariance in outcomes and treatment that is explained by observables. In other words, researchers must not only assert that they chose observables to reduce selection bias, but show that those observables do have the explanatory power to reduce selection bias. Oster derives a simple approximation of the consistent estimator for a treatment effect $\beta$,

$$
\hat{\hat{\beta}}=\hat{\beta}-\delta(\stackrel{\circ}{\beta}-\hat{\beta}) \frac{\overline{\mathbb{R}}-\hat{\mathbb{R}}}{\hat{\mathbb{R}}-\stackrel{\circ}{\mathbb{R}}},
$$

where $\hat{\beta}$ and $\hat{\mathbb{R}}$ are the estimated treatment effect and the coefficient of determination $\left(R^{2}\right)$ from the regression including observed controls; $\stackrel{\circ}{\beta}$ and $\stackrel{\circ}{\mathbb{R}}$ are the estimate and the coefficient of determination without any controls; $\delta$ is the ratio of the degree of selection on unobservables to the degree of selection on observables; and $\overline{\mathbb{R}} \equiv \Pi \hat{\mathbb{R}}$ is the coefficient of determination from a hypothetical regression that includes all important observed and unobserved controls $(\Pi>1)$. With conservative choices 
for $\delta$ and $\Pi$, (7) can bound the true treatment effect. ${ }^{7}$ Alternatively, setting $\hat{\hat{\beta}}=0$ in (7) and solving for $\delta$ allows estimation of how large selection on unobservables must be, relative to selection on observables, for the true treatment effect to be zero. Oster proposes a stringent standard for reporting results of $\delta=1$ and $\Pi=1.3$, the level of stability typically demonstrated by studies in the literature where treatment is randomized.

We can apply these standards to compute a lower bound on $R$ for each country. Table 2 carries out this bounding exercise for the wage ratios at purchasing power parity, for a 35-39 year-old male with 9-12 years of education. The first column reproduces $\hat{R}_{c}$ from Table 1 . The second column estimates lower bounds on $R$ using (7), under the robustness standard for quasi-random treatment assignment: $\Pi=1.3$ and $\delta=1$. All of these bounds remain above a treatment effect of zero $(R=1)$ and most remain very large. The lower bound on $R$ exceeds 5.0 in 17 countries and exceeds 3.0 in 29 out of 42 countries. The third column adopts the even more conservative standard of $\Pi=2$. The lower bound on $R$ is still above 1.0 for 40 out of 42 countries, and above 3.0 for 22 countries. $^{8}$

In column 4 we report the relative degree of selection on unobservables to observables

${ }^{7}$ Intuitively, if the explanatory power of the observables is much less than the amount of variance left to explain $(\hat{\mathbb{R}}-\mathbb{R} \ll \overline{\mathbb{R}}-\hat{\mathbb{R}})$, changes in the treatment effect estimate upon inclusion of observables $(-\delta(\stackrel{\beta}{\beta}-\hat{\beta}))$ become uninformative about the degree of selection on unobservables.

${ }^{8}$ For two of the countries - Yemen and Cambodia - the procedure provides upper bounds on $R$ and suggests that the original $R_{c}$ is a lower bound on $R$. 
$(\delta)$ that would be necessary in order for the estimated ratio $R_{c}$ to be consistent with $R=1$ ) using $\Pi=1.3$. The selection on unobservables would typically need to be an order of magnitude larger than selection on observables (median $\left.\delta\right|_{R=1}=12.2$, $80^{\text {th }}$ percentile 23.5) for $R$ to be unity given the observed $R_{c}$. Column 5 reports the ratio $R_{u} / R_{c}$, showing generally positive selection on observables, with a median of 1.17. The median ratio of the estimates of the coefficient-stability lower bound on $R$ is 1.12 . The median ratio of the lower bounds on $R$ in the third column $(\Pi=2)$ to $R_{c}$ is 1.44 .

Is it plausible that selection on unobservables is an order of magnitude greater than selection on observables? Several studies of migrant self-selection have recently been done, in a variety of settings, that allow calculation of the relevant parameters. Table 3 presents all estimates of which we are aware. 11 of these use panel data to compare non-migrants with subsequent migrants prior to migration. These 11 results come from a variety of settings: origin areas both rich (Finland) and poor (Tonga); policy barriers both absent (Poland) and present (Mexico); distance both short (Lithuania) and long (Micronesia); time both contemporary (Israel) and historical (Norway). None of these settings records positive selection on unobservables with $\delta$ exceeding 0.89 . In six cases there is positive selection on unobserved determinants of earnings, but the highest $R_{c} / R$ ever recorded is 1.36 . In three cases there is no appreciable selection on unobservables despite selection on observables, thus $\delta \approx 0$. In two of the cases there is negative selection on unobservables $\left(R_{c} / R<1\right)$, so that $R_{c}$ serves as a lower bound on $R$. Both are studies of Mexico-US migration; in one of these $\delta<1$ and in the other, $\delta$ reaches +2.25 . One study has used retrospectively-reported pre-migration wages for recent U.S. immigrants to estimate $\delta<\frac{1}{3}$ for a group of home countries comprising 36 of the 42 we study, and $\delta \approx 1$ 
in the rest. ${ }^{9}$ In all of these cases of positive selection on unobservables where it is possible to estimate $\delta$ given the published results, $\delta$ is approximately equal to or much less than 1.

These studies support the interpretation of column 2 of Table 2 as conservative lower bounds on $R$ (not as unbiased or consistent estimates of $R$ ). The working-age population-weighted average of the lower bounds on $R$ is 5.65. The lower bound for the median country (the Philippines) is 3.48 , and for the $80^{\text {th }}$ percentile country (India) is 5.93. The final column of Table 2 shows the dollar-value difference in PPP annual wages implied by $\left.R\right|_{\delta=1, \Pi=1.3}$. These are best interpreted as lower bounds on the price equivalent for observably and unobservably equivalent low skill, male, prime-age workers between the home country and the United States.

${ }^{9}$ Hendricks and Schoellman (2018) report relative self-selection on observable and overall wage determinants, using retrospectively recalled pre-migration earnings, for recently-arrived U.S. immigrants from five broad groups of countries. They report a graphical decomposition of selection that allows bounds on $\delta$ for recent U.S. immigrants. The large majority of self-selection on earnings determinants arises from selection on observables $(\delta \ll 1)$. For workers from the group of countries with greater than 1/16 of U.S. PPP GDP per capita (including 36 of the 42 countries studied here), they find $\delta<\frac{1}{3}$. For the very poorest countries (the other eight of the 42 countries studied here), they find $\delta \approx 1$. 


\subsection{Testing predictions of Roy-model self-selection}

We can gain more insight into the plausibility of large positive selection on unobservables by testing necessary conditions implied by theory. Here we follow Hanson's (2006) nonstochastic extension of the Roy (1951)-Borjas (1991) model of migrant self-selection, and consider selection on unobservables within observed skill groups as in Ambrosini and Peri (2012, p. 131). Suppose a worker with observed skill $s$ will migrate if U.S. wages exceed the forgone foreign wage plus migration costs: $\ln w_{\mathrm{US}}-\ln \left(w_{0}+C\right)>0$. Expressing migration cost in time-equivalent form $\left(\pi \equiv C / w_{0}\right)$, then by (1) and (2) workers migrate if unobserved skill satisfies

$$
\widetilde{s}>\frac{\pi-\left(\mu_{\mathrm{US}}^{\prime}(s)-\mu_{0}^{\prime}(s)\right)}{\widetilde{\gamma}_{\mathrm{US}}-\widetilde{\gamma}_{0}} \equiv \underline{s}(s) .
$$

This standard result implies that migrants will exhibit positive selection on unobservables if the return to unobservables at the destination exceeds the return at the origin $\left(\widetilde{\gamma}_{\mathrm{US}}>\widetilde{\gamma}_{0}\right)$. But because we have data from numerous countries, we can derive a necessary condition for bias in $R_{c}$ due to Roy selection on unobservables. From (4), (5), and (8),

$$
\left.\frac{\partial \ln \left(R_{c}(s) / R\right)}{\partial \widetilde{\gamma}_{\mathrm{US}}}\right|_{\widetilde{\gamma}_{0}}=\left.\widetilde{\gamma}_{0} \cdot \frac{\partial E[\hat{s} \mid \hat{s}>\underline{s}(s)]}{\partial \widetilde{\gamma}_{\mathrm{US}}}\right|_{\widetilde{\gamma}_{0}}>0
$$

That is, if $R_{c}$ is biased upward by positive selection on unobservables, Roy selection predicts that this bias will be greatest when the relative return to unobserved skill is higher in the destination country relative to the origin country.

We can test condition (9) by following the literature since Juhn et al. (1993) and 
considering the dispersion of $\widetilde{s}$ for workers of a given country of birth, in each country of residence ( $\sigma_{0}$ and $\sigma_{\mathrm{US}}$ ), to proxy for the corresponding returns to unobserved skill. Let $\sigma_{\mathrm{US}}(s)$ be the standard deviation of $\ln$ wage conditional on observables, from regression (6), for workers born in each country and resident in the United States. Let $\sigma_{0}(s)$ be the same conditional standard deviation for workers resident in the country of birth. Thus $\sigma_{\mathrm{US}}(s)-\sigma_{0}(s)$ proxies for $\widetilde{\gamma}_{\mathrm{US}}(s)-\widetilde{\gamma}_{0}(s)$, the returns to unobserved skill in the United States relative to the country of birth, specific to each observed skill group.

Figure 1 tests for the relationship (9) by graphing $R_{c}$ against $\sigma_{\mathrm{US}}(s)-\sigma_{0}(s)$, by country, separately for each of three observed skill groups. ${ }^{10}$ For example, Figure 1a plots $R_{c}$ against $\hat{\sigma}_{\mathrm{US}}(s)-\hat{\sigma}_{0}(s)$ for workers with $5-8$ years of education only, across all countries. There is no positive correlation between the estimates of $R_{c}$ and the relative returns to unobserved skill, contrary to what theory predicts if positive selection is an important source of bias. If anything, the relationship is negative. This suggests that positive selection on unobservables predicted by the Roy model could not be a first-order determinant of the magnitude of the estimates $R_{c}$. Egypt and Yemen are slight outliers.

\subsection{Testing for self-selection due to borrowing constraints}

Theory predicts another reason why migrants might exhibit positive self-selection on unobserved determinants of wages. While migrant selection theory has traditionally

\footnotetext{
${ }^{10}$ The full estimates of $R_{c}$ and $\sigma_{\mathrm{US}}(s)-\sigma_{0}(s)$ separately by education group are in the Appendix.
} 
focused on Roy selection, a recent literature has stressed borrowing constraints as an important determinant of selection. ${ }^{11}$ Workers with low earnings for unobservable reasons may simply be unable to afford the costs of migration, broadly considered, so that migrants have levels of unobserved skill that exceed the average in the origin country.

Again extending Hanson (2006) to the case of selection on unobservables within observed skill groups, suppose that income $y_{0}$ of a worker in the origin country is a function of unobserved skill. For workers of observed skill $s, y_{0}(s)=\widetilde{\xi}_{0}(s)+\widetilde{\nu}_{0}(s) \hat{s}$, where $\widetilde{\xi}_{0}, \widetilde{\nu}_{0}>0$. Some workers cannot pay the migration cost $C(s)$, which is a function of observed skill, but can borrow it if they hold collateral $\psi C(s), \psi>0$. The condition for migration becomes

$$
\hat{s}>\frac{\psi C(s)-\widetilde{\xi}_{0}(s)}{\widetilde{\nu}_{0}(s)} \equiv \underline{\underline{s}}(s) .
$$

That is, positive selection on unobservables arises within observed skill groups because those with the highest unobserved determinants of earnings are the ones most likely to be able to acquire the necessary assets. This force for positive selection can act independently of Roy selection (8).

We can use condition (10), as we used (8), to make predictions about patterns the

${ }^{11} \mathrm{~A}$ wave of studies have stressed the effect of poverty and credit constraints on selection in contemporary migration (McKenzie and Rapoport 2010; Hanson 2010; Gould and Moav 2016). This mechanism has also been important in the economic history literature on earlier migration flows (Hatton and Williamson 2006; Abramitzky et al. 2012). 
data should contain if selection of this kind is driving the results. Suppose that migration costs are lower for high-observed-skill workers $\left(\frac{\partial C}{\partial s}<0\right)$ and that wealth and the wealth-returns to unobserved skill are greater for workers with higher observed skill $\left(\frac{\partial \widetilde{\xi}_{0}}{\partial s}>0, \frac{\partial \widetilde{\nu}_{0}}{\partial s}>0\right)$. Both of these are plausible: many countries actively encourage high (observed) skill migration while obstructing low (observed) skill migration. And workers in developing countries with higher observed skill typically have greater wealth and work in complex occupations with higher returns to unobserved skill than menial occupations. Suppose furthermore that credit constraints bind for workers without any observed skill $\left(\psi>\frac{\widetilde{\xi}_{0}(s)}{C(s)}\right)$. Together, these imply

$$
\frac{\partial \ln R_{c}(s) / R}{\partial s}=\frac{\partial E[\hat{s} \mid \hat{s}>\underline{\underline{s}}(s)]}{\partial s}<0
$$

That is, if the estimates of $R_{c}$ are systematically biased upward from $R$ because of self-selection on unobservables arising from poverty constraints, then we should see estimates of $R_{c}$ decline when higher and higher levels of observed skill are considered separately.

This test is possible with the information already discussed in the previous subsection: separate estimates of $R_{c}$ for each education group: 5-8 years, 9-12 years, and $13+$ years. $^{12}$ In 8 countries, $R_{c}$ is higher for workers with $13+$ years of education than for workers with 5-8 years of education, which is incompatible with (11). In the other 34 countries $R_{c}$ falls somewhat at higher levels of observed skill, which is compatible with (11). The median ratio $R_{c}(5-8$ years $) / R_{c}(13+$ years $)$ is 1.38 . Collectively, this evidence is compatible with modest positive selection on unobservables

\footnotetext{
${ }^{12}$ The full results are presented in the Appendix.
} 
that induces upward bias in $R_{c}$ as an estimate of $R$ to a degree comparable to the independent estimates of this bias from Table 2. In other words, to the extent that marginal workers who can afford university education can also afford migration, $R_{c}$ for workers with $13+$ years of education can serve as a lower bound on $R$ for that category of worker.

A second test uses the fact that in the credit-constraint theory of positive selection, unlike in Roy selection, selection on observables and unobservables must go in the same direction. In this theory the poor do not migrate because they do not have the money, and from the standpoint of theory it does not matter whether the reason they do not have money is due to observable or unobservable traits. Take Hanson's (2006) observable counterpart to the wealth equation above and suppose that wealth is also positively correlated with observed skill: $y_{0}(s)=\xi_{0}+\nu_{0} s$, where $\xi_{0}, \nu_{0}>0$. Migrants are positively selected on observed skill analogously to (10), and just as above we can derive an observable counterpart to condition (11):

$$
\frac{\partial \ln R / R_{c}(s)}{\partial \ln w_{0}}<0
$$

with the innocuous assumption that income correlates positively with wealth. That is, if positive self-selection on observables arises due to poverty constraints, the degree of positive self-selection should fall as average wages rise.

Figure 2 carries out this test, plotting the degree of selection on observables $\left(\ln R_{u} / R_{c}\right)$ against $E\left[w_{0}\right]$ for all countries of birth, and each observed skill group. The pattern predicted by (12) is not present across all the countries at any level of observed skill. For workers of 5-8 years of education this is perhaps no surprise, since there 
is less scope for positive selection on education. For higher levels of observed skill, the pattern is more informative. For workers with 9-12 years of education, the degree of positive selection on observables is roughly the same in Costa Rica and Argentina as it is in Vietnam and Sierra Leone, despite a fourfold difference in average wages. The conditional mean does fall slightly, from about 1.4 to 1.2, as the average wage ranges over an order of magnitude. This is consistent with a modest upward bias on $R_{u}$ as an estimate of $R_{c}$ due to selection on observables arising from credit constraints. For the most educated workers (13+ years of education), the conditional mean changes little between the average wage of PPP $\$ 300 /$ month and PPP $\$ 1,200 /$ month. It does fall by roughly 0.3 log points over the range PPP $\$ 600$ $1,200 /$ month. This too is compatible with modest upward bias arising from positive selection on observables due to credit constraints. ${ }^{13}$ The simple theory presented here does not suggest a reason why income that reflects observables should affect credit constraints differently from income that reflects unobservables. ${ }^{14}$

\footnotetext{
${ }^{13}$ At extremely low wages, $\operatorname{PPP} \$ 100-250 /$ month, the conditional mean of $\ln R / R_{c}(s)$ rises with the wage for 9-12 years of education and $13+$ years of education. This pattern could arise if, in these extremely poor countries, even the university educated face binding credit constraints. This evidence is compatible with binding credit constraints for potential migrants in Cambodia, Egypt, Haiti, Nigeria, Yemen, and perhaps Sierra Leone. In other words, we should consider with caution the estimates $R_{c}$ that greatly exceed 10 .

${ }^{14}$ Note that the global sample of workers here is restricted to employed wageworkers. The poorest of the poor-self-employed farmers or small-time informal retailers - are not included and these conclusions regarding credit constraints do not apply to them.
} 
A third and separate test for bias due to positive selection of this kind takes advantage of information contained in the relative performance of migrants and natives in the U.S. labor market. Suppose that U.S. natives' wages, analogously to (1) and $(2)$, are determined by $w^{*}(s)=\left(\mu_{0}^{*}+\gamma_{0}^{*} s\right)+\widetilde{\gamma}_{0}^{*} \widetilde{s}$ and natives' unobserved skill has mean zero. Migrants' skill is only partially transferable, as in the model advanced by Gould and Moav (2016). Observed skill is transferable from the migrant-origin country to the U.S. in the proportion $\gamma_{\mathrm{US}} / \gamma_{0}$, and unobserved skill is transferable in the proportion $\widetilde{\gamma}_{\mathrm{US}} / \widetilde{\gamma}_{0}$. We can express the wages of a migrant in the U.S. as

$$
E_{\mathrm{US}}\left[\ln w_{\mathrm{US}}\right]=E\left[\ln w^{*}\right]-\left(1-\frac{\gamma_{\mathrm{US}}}{\gamma_{0}}\right) E\left[\ln w^{*}-\ln \underline{w}\right]+\widetilde{\gamma}_{\mathrm{US}} E_{\mathrm{US}}[\hat{s}]
$$

where $\underline{w}^{*}$ is the wage of a U.S. worker with no observable skill (no education, no experience), and $E_{\mathrm{US}}$ denotes expectations for migrant workers in the U.S. The identity (13) states that the average wage of a migrant worker in the U.S. equals the average wage of an observably equivalent U.S. worker, minus the portion of migrant workers' observable wage determinants that do not transfer from the origin country to the U.S., plus the U.S. returns to migrants' unobservable skill. In the limiting case where none of migrants' observable skills are valued in the U.S. market $\left(\gamma_{\mathrm{US}} / \gamma_{0}=0\right)$ and migrants are neutrally selected on unobservables $\left(E_{\mathrm{US}}[\hat{s}]=0\right)$, all migrants regardless of observed or unobserved skill have the earnings of a U.S. teenager with no schooling. From (4) and (5) we have $\ln \frac{R_{c}}{R}=\widetilde{\gamma}_{0} E_{\mathrm{US}}[\hat{s}]$, into which we substitute (13) to get

$$
E_{\mathrm{US}}\left[\ln w_{\mathrm{US}}\right]-E\left[\ln w^{*}\right]=\frac{\widetilde{\gamma}_{\mathrm{US}}}{\widetilde{\gamma}_{0}}\left(\ln R_{c}-\ln R\right)-\left(1-\frac{\gamma_{\mathrm{US}}}{\gamma_{0}}\right) E\left[\ln w^{*}-\ln \underline{w}^{*}\right]
$$

Intuitively, migrants who are more positively selected on unobserved skill $\left(R_{c}>R\right)$ 
should earn more relative to natives of the same observable skill, to the extent that their unobserved skill is transferable $\left(\widetilde{\gamma}_{\mathrm{US}} / \widetilde{\gamma}_{0}\right)$. If there are zero returns to migration ( $R=1$ ), a regression of $R_{c}$ on the native-immigrant wage gap within an observed skill group should have slope representing the transferability of unobserved skill. If that slope is zero, then either unobserved skill is completely untransferable - it does not represent IQ, energy, risk tolerance, or anything else that comes with migrants and has returns in the U.S. - or $R_{c} \approx R$.

We calculate $E_{\mathrm{US}}\left[w_{\mathrm{US}}\right]-E\left[w^{*}\right]$ for each country of birth and three observed education groups, always for 35-39 year-old males. ${ }^{15}$ This allows us to run the regression (14) nonparametrically in Figure 3.

The slope is generally indistinguishable from zero across most of the support of $R_{c}$, for all three observed skill groups. Two exceptions, in workers with 5-8 years of education, are Cameroon and Morocco. This suggests that either unobserved skill exhibits near-zero transferability to the U.S. labor market, or that estimates of $R_{c}$ do not greatly exceed $R$. Research that compares U.S. immigrants' earnings to their pre-migration earnings estimates that the transferability of foreign unobserved skill is 0.34 shortly after arrival (Jasso et al. 2002), a lower bound on $\widetilde{\gamma}_{\text {US }} / \widetilde{\gamma}_{0}$ since the returns to migrants' unobserved skill rise in the years following arrival (Chiswick and Miller 2012). This suggests that the gap between $R$ and $R_{c}$ is not large.

We can use this information to estimate a rough bound on the selection bias $R_{c} / R$. For the observed skill group with the most positive slope in Figure 3 (5-8 years of schooling), a linear regression of $E_{\mathrm{US}}\left[w_{\mathrm{US}}\right]-E\left[w^{*}\right]$ on $\ln R_{c}$ gives the slope 0.144

\footnotetext{
${ }^{15}$ The full estimates are in the Appendix.
} 
(standard error 0.061). If a lower bound on the transferability of unobserved skill for those who have chosen to migrate is 0.34 , this puts an upper bound on $R_{c} / R$ of $e^{(0.144 / 0.34)}=1.53$ for workers with $5-8$ years of education. For the group with $13+$ years of schooling, the linear regression slope is 0.031 (standard error 0.043), and the corresponding upper bound on $R_{c} / R$ is $e^{(0.031 / 0.34)}=1.10$. These estimates independently corroborate the approximate magnitude of bias estimated above. The declining bias at higher observed skill also agrees with the prediction of (11).

These results are consistent with modest systematic bias in $R_{c}$ as an estimator of $R$ due to positive selection on unobservables arising from credit constraints. Incidentally, these results also have implications for the discussion of Roy selection in subsection 3.2. The slopes in Figure 3 further suggest that Roy selection is unlikely to create a large upward bias on $R_{c}$ as an estimate of $R$. A well-known prediction of Roy selection is that positive selection on unobservables cannot occur without positive returns to unobservables in the destination country. ${ }^{16}$ The flat slopes in the figure imply either that almost none of migrants' unobserved skill is transferable to the destination country, or that $R_{c} \approx R$. But if migrants' unobserved skill is not

${ }^{16}$ Formally, if $\widetilde{\gamma}_{\mathrm{US}}=0$ then condition (8) flips to $\widetilde{s}<\frac{\left(\mu_{\mathrm{US}}^{\prime}-\mu_{0}^{\prime}\right)-\pi}{\tilde{\gamma}_{0}}$, and those with below-average unobserved skill choose to migrate. In terms of the stochastic Roy model in Borjas (1991), when earnings at the destination are uncorrelated with earnings at the origin $(\rho=0)$, then as long as $\sigma_{0}>0$, selection must be negative. Intuitively, if all migrants within an observed skill group had exactly the same wage at the destination (zero return to unobserved skill), then those with the most to gain from migration must be those with the lowest levels of unobserved skill-provided that unobserved skill has any positive return in the origin country. 
transferable, the Roy model predicts negative selection on unobservables. In that case the estimates of $R_{c}$ would generally serve as a lower bound on $R$.

A final and intuitive robustness check, presented in the Appendix, is to simply truncate the very poorest workers from the analysis. The findings are robust to this change. After dropping workers below $\mathrm{PPP} \$ 4 /$ day, the median ratio of $R_{c}$ to the original result in Table 1 is 1.07 .

\subsection{Summary of findings}

The various methods used here to place bounds on $R$ broadly agree. Coefficient stability and diverse existing evidence about selection on unobservables imply that for the median country, $R>3.95$ (Table 2 ) and for the $80^{\text {th }}$ percentile country, $R>6.14$. These correspond to lower bounds on the absolute gain per worker per year of $\mathrm{PPP} \$ 13,600$ and $\mathrm{PPP} \$ 15,600$, respectively. The corresponding upper bounds on the degree of selection on unobservables, $R / R_{c}$, are 1.12 at the median and 1.26 at the $80^{\text {th }}$ percentile. Various robustness checks corroborate these bounds: The predictions of Roy self-selection are incompatible with $R / R_{c}$ outside this range (Figure 1). The predictions of borrowing-constraint self-selection (Figure 3) are compatible with $R / R_{c}$ in the middle of the range 1.1-1.5 (for the 9-12 years of schooling group). Dropping all workers in poverty leads to $R / R_{c}$ of 1.1 for the median country. In 11 studies allowing point estimates of $R / R_{c}$ for a real migration flow, most values are close to unity and the highest ever recorded is 1.36. In all studies of real migration flows, when there is positive selection on unobservables it is of a degree roughly equal to the degree of selection on observables in extreme cases, and much less in typical cases. 


\section{Discussion: Policy barriers and natural barriers}

The place premium $R$ measures an aggregate of two different kinds of costs. In a labor market at full spatial equilibrium workers move until the marginal benefit equals the marginal cost, thus $R=w_{\mathrm{US}} / w_{0}=1+\pi$. Part of the cost $\pi$ could arise from barriers induced by policy such as visa fees, smuggler fees, or the price equivalent of visa rationing or professional licensing restrictions. Another part could arise from barriers largely independent of policy such as transportation costs or nonwage disamenities, such as a compensating differential for being far from home. Since the Elements of Marshall (1892, p. 282) it has been recognized that "the unwillingness to quit home, and to leave old associations, including perhaps some loved cottage and burial-ground, will often turn the scale against a proposal to seek better wages in a new place."

These two types of migration barriers cannot be cleanly distinguished in the data used here. Beyond that, it is difficult to distinguish 'natural' and 'policy' barriers to migration even in theory. For example, migrant networks are known to be an important determinant of migration costs by reducing search frictions (Munshi 2003) and credit constraints (McKenzie and Rapoport 2010). Costs arising from a small network could be modeled as 'natural' barriers. But networks reflect prior migration flows, and those flows were themselves a consequence of policy. Generations of U.S. 'national origin' quotas were designed expressly to prevent migration from much of Southern Europe, Africa, the Middle East, and Asia, and did so (Higham 2002, p. 312-324). Language barriers and other disamenities of migration, too, can be modeled as 'natural' barriers. But such costs are shaped by policy: for example, 
while in recent years the state of New Hampshire required its driving knowledge exam to be taken exclusively in English, neighboring Vermont allowed the same test to be taken in three foreign languages.

Here we discuss reasonable priors for the fraction of the place premium that arises from barriers that are unambiguously related to policy. While a quantitative decomposition is impossible, information is available to form reasonable qualitative priors about the fraction of the place premium that arises from policy barriers. To begin with, most people outside the United States are prohibited by default from entering the country and working there unless they acquire a special license from the federal government, a visa. This includes citizens of all 42 countries we study. Such policy barriers have large effects on migration flows. Bertoli and FernándezHuertas (2015) find that visa requirements cut bilateral migration flows by half at equilibrium, while any new law tightening immigration policy typically reduces inflows by $6 \%$ in the same year Ortega and Peri (2013). Many U.S. visas are tightly rationed, with waiting periods measured in decades. ${ }^{17}$ The United States government spends more on enforcing its immigration restrictions than it spends on all other principal federal law-enforcement agencies combined - including the Federal Bureau of Investigation, the Drug Enforcement Administration, and the Bureau of Alcohol, Tobacco, and Firearms (Meissner et al. 2013, p. 22). It would be strange if cross-border labor markets were unaffected by all of this, given that policies en-

\footnotetext{
${ }^{17}$ An example of a tightly binding quota is the U.S. Diversity Visa: for each person granted such a visa in 2015, there were 288 qualified applicants $(14,397,781$ qualified applicants for 50,000 visas). Waiting periods are over ten years for many categories of family-based visas for citizens of China, India, Mexico, and the Philippines.
} 
forced at borders have large price effects on output prices and other factor prices (e.g. Anderson and van Wincoop 2004). These suggest a reasonable starting prior that the fraction of the wage gap $R$ related to policy is substantial.

An ideal natural experiment to isolate policy costs would require countries that are highly similar to the 42 countries studied above, but do not face policy barriers on U.S. immigration. There are no areas so similar in all other respects as to allow precise decomposition of the 'policy' portion and 'natural' portion of the place premium. There do exist territories free of policy barriers that are nevertheless similar in some respects to foreign countries. People from Puerto Rico and Guam hold U.S. citizenship and can live and work at will to any part of the United States. The estimates of $R_{c}$ for these areas without policy barriers - Puerto Rico and Guam-lie in the range $1.3-1.5$, substantially above unity. ${ }^{18}$ This is compatible with sizeable natural barriers to migration even for workers who face no policy barriers. But these estimates are much smaller than those in Table 1. The ratio for Haiti is several times the size of the ratio for Puerto Rico, even though both countries are close to the United States and have large migrant networks there. The ratio for the Philippines is several times the size of the ratio for Guam, even though both countries are very far from the United States and both likewise have large migrant networks. There are other ways that Puerto Rico and Guam differ from foreign countries-Puerto Rico receives sizeable inflows of Social Security payments, Guam hosts three U.S. military bases - thus these figures are only suggestive.

But Puerto Rico and Guam are not exceptional. It is difficult to find labor markets

\footnotetext{
${ }^{18}$ These regressions are presented in the Appendix.
} 
anywhere on earth that sustain real wage differentials $R_{c}$ much above 1.5 across geographic areas in the absence of policy restrictions on migration. Kennan and Walker (2011, p. 246) find that 34 year-old men in the United States have typically forgone a multiple of 1.21 in wage-equivalent utility gains that they could have reaped from an interstate move at age 20, reflecting the fact that moving incurs disutility from the loss of a "home premium" and climate amenities. Burda (1995, p. 3) finds that $R_{c}$ between West Germany and East Germany collapsed to 1.3 in the years after policy barriers to migration were eliminated and migration flows spiked. Real wage differentials between metropolitan France and French overseas departments/territories, which exhibit no policy barriers to migration, fall in the range 1.2-1.4. ${ }^{19}$ This broad pattern holds in historical episodes of international migration without policy barriers. Abramitzky et al. (2012) find $R_{c}<1.7$ for late $19^{\text {th }}$ century migration from Norway to the United States. ${ }^{20}$ Williamson $(1999$, p. 124) shows that $R_{c}$ collapsed from as high as 4 to around 1.5 as migration soared from the Mediterranean to the New World 1880-1914, with falling transportation costs and absent policy restrictions.

\footnotetext{
${ }^{19}$ Between metropolitan France and faraway Réunion, $R_{c}=1.18$ [the euro wage gap for typical private-sector low-skill workers (ouvriers) is 18,820/17,970, and prices are 12.4\% higher in Réunion (INSEE 2014, pp. 69, 121)]. For Guadeloupe it is 1.35 [the euro wage gap for moderately low-skill males (ouvriers qualifiés) is 15,937/13,556 (INSEE 2010, p. 105), and prices are 14.8\% higher in Guadeloupe (INSEE 2014, p. 121)].

${ }^{20}$ Abramitzky et al. (2012) estimate $R=1.7$, an upper bound on $R_{c}$ due to negative selection on observables for urban workers.
} 
These estimates suggest limited scope for explaining the very large estimates of $R_{c}$ and $R$ in the preceding sections with natural barriers like pure transportation costs, or Marshall's fondness-for-home. Wage gaps are an order of magnitude smaller in many settings that exhibit transportation costs and fondness for home, but do not exhibit policy restrictions. A reasonable prior is that a substantial portion of the large gaps measured in this paper arise from policy barriers, though precisely what portion we cannot estimate here. That portion is likely to vary considerably across different countries.

Under different assumptions about the relative effects of policy and non-policy barriers on $R$, we can construct scenarios for the supply price of labor from different countries. Figure 4 carries out this exercise. The thick black line shows $\bar{w}_{0}$, an upper bound on the unobserved home-country earnings of workers fully equivalent to those observed living in the United States, for 35-39 year old males with 9-12 years of foreign education. These are calculated using the lower bounds on $R$ from Table 2, column $2(\delta=1, \Pi=1.3)$. The vertical axis shows annual \$PPP wages, and the horizontal axis shows cumulative working-age population of the source countries with $\bar{w}_{0}$ at or below each value. The black line, then, can be interpreted as the upper envelope for the curve of forgone home-country wages for existing migrants. Directly above each country's flat step in that curve is a dash indicating the wages of fully equivalent migrants born and educated in that country who work in the U.S., and a dashed line shows the simple average of that wage across all immigrants. A further dashed line at the top of the graph shows the corresponding U.S. wage for the U.S.-born.

What would the supply curve of foreign labor in the U.S. market look like with a 
different mix of policy and natural barriers? We cannot estimate that curve because we cannot precisely decompose $R$ into policy and non-policy elements. But Figure 4 also shows what the upper envelope of that supply curve would look like if wage ratios in the absence of policy barriers were 1.5, as discussed above, or the more extreme case of 2.0. Even in the more extreme case, the distortion arising from policy barriers would, at the margin, exceed $\mathrm{PPP} \$ 10,000$ per worker per year for over a billion working-age people in the countries studied here. That would place the magnitude of the implied Harberger triangle plausibly in the trillions of dollars per year. This is not an estimate of the distortion from policy barriers, but is a lower bound on the magnitude of the distortion if real wage ratios above 2.0 cannot be sustained without policy barriers.

In one sense the wages-forgone curve in Figure 4 is conservatively high, and the implied loss conservatively low. Subsection 3.3 considered borrowing constraints as a theoretical reason for positive selection on unobservables $\left(R>R_{c}\right)$. McKenzie and Rapoport (2010) find that such borrowing constraints induce positive selection among Mexico-U.S. migrants, but when those borrowing constraints are alleviated by migrant networks, selection is negative. Lesser policy barriers to migration would naturally tend to increase the size of migrant networks. This would allow poorer people to migrate, raising $R$ and reducing $\bar{w}_{0}$. In other words, if positive selection arises from borrowing constraints then policy barriers also shape selection. The estimates $\bar{w}_{0}$ are conservatively high to account for extensive positive selection, but the borrowing-constraint theory predicts that such positive selection arises in part from policy barriers themselves. 


\section{Conclusion}

We have estimated real wage gaps between migrants from 42 countries in the United States and observably equivalent workers in the origin country. Focusing on male workers in their late thirties with 9-12 years of education, we estimate that for workers from the median country this ratio $\left(R_{c}\right)$ is 4.54 , for the $80^{\text {th }}$ percentile country it is 7.58 , and the working-age population weighted average is 6.83 . We use a variety of independent methods to bound the plausible bias in these ratios as estimates of the real wage gap for fully equivalent workers $(R)$ that could arise from positive selection of migrants on unobservable determinants of wages.

These bounds imply that workers migrating from the median country to the United States raise their real earnings by a factor greater than 3.95 (an absolute gain ex-

ceeding $\operatorname{PPP} \$ 13,600 /$ year $)$, while workers from the $80^{\text {th }}$ percentile country raise their real wages by a factor greater than 6.14 (an absolute gain exceeding $\$ 15,600$ per year). Real wage gaps in the hundreds of percent for workers of equal inherent productivity appears to be a striking feature of the current global economy. This independently corroborates macroeconomic findings of large productivity gaps between countries that arise from places rather than people (Caselli 2005; Acemoğlu and Dell 2010; Jones 2016). It likewise suggests that each type of migration barriers, both natural and policy barriers, creates Harberger triangles in the global economy that measure in the trillions of dollars per year. Further research should more precisely estimate rather than simply bound the real wage gaps $R$, and a priority should be to empirically isolate the portion of this place premium that arises from migration policy. 


\section{References}

Abramitzky, Ran, Leah Platt Boustan, and Katherine Eriksson, "Europe's Tired, Poor, Huddled Masses: Self-Selection and Economic Outcomes in the Age of Mass Migration," American Economic Review, 2012, 102 (5), 1832-1856.

Acemoğlu, Daron and Melissa Dell, "Productivity Differences Between and Within Countries," American Economic Journal: Macroeconomics, 2010, 2 (1), $169-188$.

Akee, Randall et al., "Who Leaves? Deciphering Immigrant Self-Selection from a Developing Country," Economic Development and Cultural Change, 2010, 58 (2), 323-344.

Altonji, Joseph G, Todd E Elder, and Christopher R Taber, "Selection on Observed and Unobserved Variables: Assessing the Effectiveness of Catholic Schools," Journal of Political Economy, 2005, 113 (1), 151-184.

Ambrosini, J William and Giovanni Peri, "The determinants and the selection of Mexico-US migrants," The World Economy, 2012, 35 (2), 111-151.

_ , Karin Mayr, Giovanni Peri, and Dragos Radu, "The selection of migrants and returnees in Romania," Economics of Transition, 2015, 23 (4), 753-793.

Anderson, James E and Eric van Wincoop, "Trade Costs," Journal of Economic Literature, 2004, $42(3), 691-751$.

Ashenfelter, Orley C., "Comparing Real Wage Rates: Presidential Address," American Economic Review, 2012, 102 (2), 617-642.

Barham, Bradford and Stephen Boucher, "Migration, remittances, and in- 
equality: estimating the net effects of migration on income distribution," Journal of Development Economics, 1998, 55 (2), 307-331.

Benhabib, Jess and Boyan Jovanovic, "Optimal Migration: A World Perspective," International Economic Review, 2012, 53 (2), 321-348.

Bertoli, Simone and Jesús Fernández-Huertas, "The size of the cliff at the border," Regional Science and Urban Economics, 2015, 51, 1-6.

Borjas, George J, "Immigration and Self-Selection," in John M Abowd and Richard B Freeman, eds., Immigration, Trade, and the Labor Market, Cambridge, MA: National Bureau of Economic Research, 1991, pp. 29-76.

Brücker, Herbert and Cécily Defoort, "Inequality and the self-selection of international migrants: theory and new evidence," International Journal of Manpower, 2009, 30 (7), 742-764.

Budnik, Katarzyna B, "Rationality of Post-Accession Migration," Focus on European Economic Integration, 2009, Q1/09, 57-83.

Burda, Michael C, "Migration and the option value of waiting," Economic and Social Review, 1995, 27 (1), 1-19.

Caselli, Francesco, "Accounting for cross-country income differences," in Philippe Aghion and Steven N. Durlauf, eds., Handbook of Economic Growth, Vol. 1A, Elsevier, 2005, pp. 679-741.

Chiquiar, Daniel and Gordon H Hanson, "International Migration, SelfSelection, and the Distribution of Wages: Evidence from Mexico and the United States," Journal of Political Economy, 2005, 113 (2), 239-281.

Chiswick, Barry R and Paul W Miller, "Negative and positive assimilation, 
skill transferability, and linguistic distance," Journal of Human Capital, 2012, 6 (1), 35-55.

Clemens, Michael A, "Economics and Emigration: Trillion-Dollar Bills on the Sidewalk?," Journal of Economic Perspectives, 2011, 25 (3), 83-106.

Collins, William J and Marianne H Wanamaker, "Selection and Economic Gains in the Great Migration of African Americans: New Evidence from Linked Census Data," American Economic Journal: Applied Economics, 2014, 6 (1), $220-252$.

di Giovanni, Julian, Andrei A Levchenko, and Francesc Ortega, "A global view of cross-border migration," Journal of the European Economic Association, 2015, 13 (1), 168-202.

Dustmann, Christian, Tommaso Frattini, and Anna Rosso, "The effect of emigration from Poland on Polish wages," Scandinavian Journal of Economics, $2015,117(2), 522-564$.

Edwards, Sebastian et al., "How Effective Are Capital Controls?," Journal of Economic Perspectives, 1999, 13 (4), 65-84.

Elsner, Benjamin, "Does emigration benefit the stayers? Evidence from EU enlargement," Journal of Population Economics, 2013, 26 (2), 531-553.

Fernández-Huertas, Jesús, "New evidence on emigrant selection," Review of Economics and Statistics, 2011, 93 (1), 72-96.

Friedberg, Rachel, "You Can’t Take It with You? Immigrant Assimilation and the Portability of Human Capital," Journal of Labor Economics, 2000, 18 (2), $221-51$. 
Gould, Eric D. and Omer Moav, "Does High Inequality Attract High Skilled Immigrants?," Economic Journal, 2016, 126 (593), 1055-1109.

Hanson, Gordon H, "Illegal Migration from Mexico to the United States," Journal of Economic Literature, 2006, 44 (4), 869-924.

_ , "International Migration and the Developing World," in Dani Rodrik and Mark Rosenzweig, eds., Handbook of Development Economics, Vol. 5, Elsevier, 2010, pp. $4363-4414$.

Hatton, Timothy and Jeffrey Williamson, "International Migration in the Long-Run: Positive Selection, Negative Selection and Policy," in Federico Foders and Rolf J Langhammer, eds., Labor Mobility and the World Economy, Springer, 2006.

Hendricks, Lutz, "How Important Is Human Capital for Development? Evidence from Immigrant Earnings," American Economic Review, 2002, 92 (1), 198-219.

_ and Todd Schoellman, "Human Capital and Development Accounting: New Evidence from Wage Gains at Migration," Quarterly Journal of Economics, 2018, forthcoming.

Higham, John, Strangers in the Land: Patterns of American Nativism, 18601925, New Brunswick: Rutgers University Press, 2002.

Hummels, David, "Transportation Costs and International Trade in the Second Era of Globalization," Journal of Economic Perspectives, 2007, 21 (3), 131-154.

INSEE, Tableaux Économiques Régionaux de Guadeloupe 2009-2010, Paris: Institut national de la statistique et des études économiques, 2010.

_, Tableau économique de La Réunion, Paris: Institut national de la statistique et 
des études économiques, 2014.

Jasso, Guillermina, Mark R Rosenzweig, and James P. Smith, "The Earnings of U.S. Immigrants: World Skill Prices, Skill Transferability and Selectivity," Working Paper, New Immigrant Survey: Princeton University 2002.

Jones, Charles I, "The Facts of Economic Growth," in John B. Taylor and Harald Uhlig, eds., Handbook of Macroeconomics, Vol. 2, Amsterdam: Elsevior, 2016, pp. 3-69.

Juhn, Chinhui, Kevin Murphy, and Brooks Pierce, "Wage Inequality and the Rise in Returns to Skill," Journal of Political Economy, 1993, 101 (3), 410-42.

Kennan, John, "Open borders," Review of Economic Dynamics, 2013, 16 (2), L1-L13.

_ and James R Walker, "The effect of expected income on individual migration decisions," Econometrica, 2011, 79 (1), 211-251.

Marshall, Alfred, Elements of Economics, Vol. 1, London: MacMillan and Co., 1892.

McKenzie, David and Hillel Rapoport, "Self-selection patterns in Mexico-US migration: the role of migration networks," Review of Economics and Statistics, 2010, 92 (4), 811-821.

_, John Gibson, and Steven Stillman, "How Important Is Selection? Experimental vs. Non-Experimental Measures of the Income Gains from Migration," Journal of the European Economic Association, 2010, 8 (4), 913-945.

Meissner, Doris, Donald M Kerwin, Muzaffar Chishti, and Claire Bergeron, Immigration Enforcement in the United States: The Rise of a Formidable 
Machinery, Washington, DC: Migration Policy Institute, 2013.

Milanovic, Branko, "Global Inequality of Opportunity: How Much of Our Income Is Determined by Where We Live?," Review of Economics and Statistics, 2015, $97(2), 452-460$.

Munshi, Kaivan, "Networks in the Modern Economy: Mexican Migrants in the US Labor Market," Quarterly Journal of Economics, 2003, 118 (2), 549-599.

Ortega, Francesc and Giovanni Peri, "The effect of income and immigration policies on international migration," Migration Studies, 2013, 1 (1), 47-74.

Oster, Emily, "Unobservable Selection and Coefficient Stability: Theory and Evidence," Journal of Business Economics and Statistics, 2018, forthcoming.

Ramos, Fernando, "Out-migration and return migration of Puerto Ricans," in George J. Borjas and Richard B. Freeman, eds., Immigration and the Workforce: Economic Consequences for the United States and Source Areas, Chicago: University of Chicago Press, 1992, pp. 49-66.

Rooth, Dan-Olof and Jan Saarela, "Selection in migration and return migration: Evidence from micro data," Economics Letters, 2007, 94 (1), 90-95.

Roy, Andrew Donald, "Some thoughts on the distribution of earnings," Oxford Economic Papers, 1951, 3 (2), 135-146.

Williamson, Jeffrey G, "Real wages, inequality and globalization in Latin America before 1940," Revista de Historia Económica/Journal of Iberian and Latin American Economic History, 1999, 17 (S1), 101-142. 
Table 1: Wage differences: observably equivalent workers, purchasing power parity

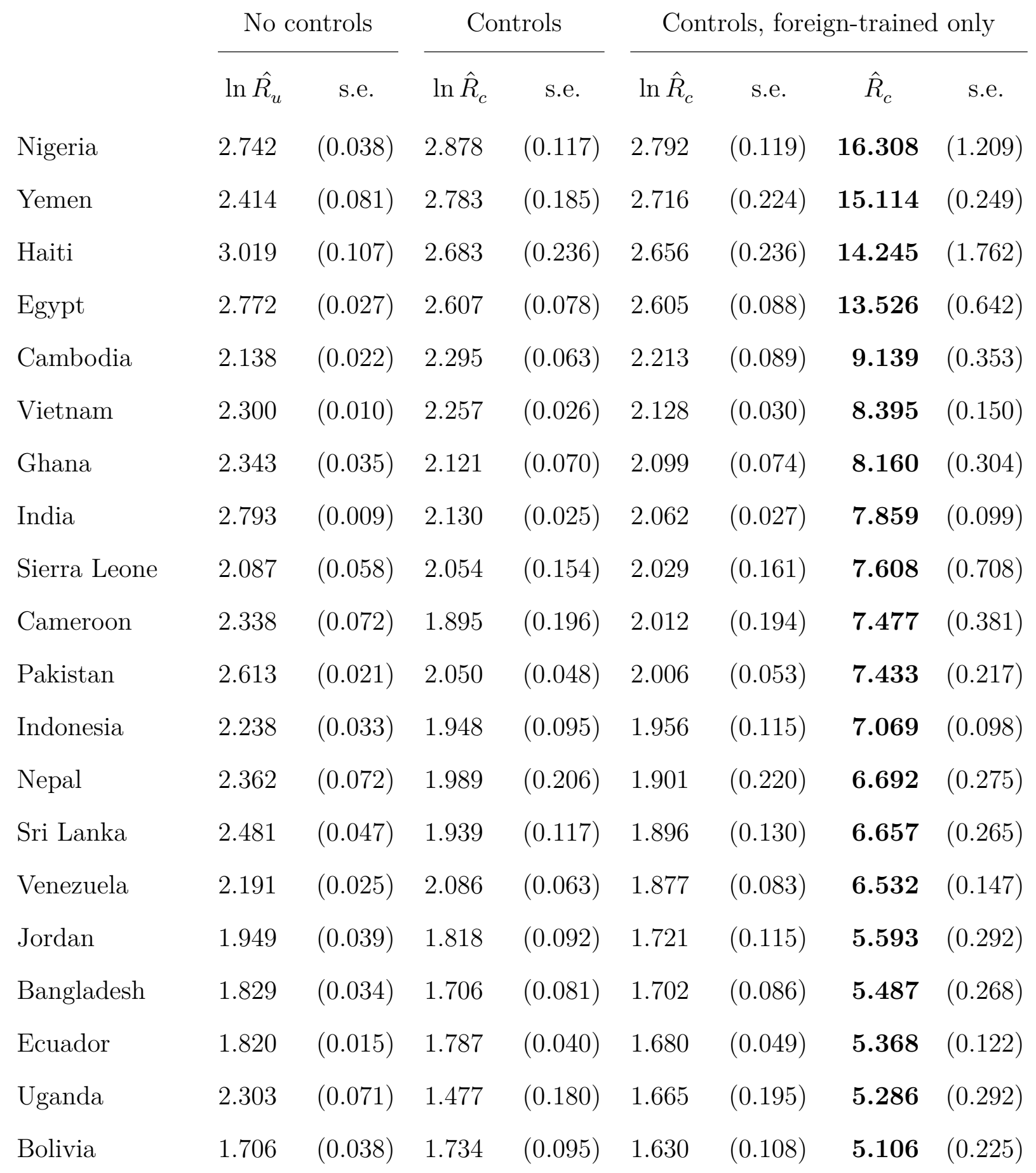




\begin{tabular}{|c|c|c|c|c|c|c|c|c|}
\hline hiopia & .492 & $(0.028)$ & 1.553 & $(0.068)$ & 1.523 & $(0.076)$ & 4.585 & $.084)$ \\
\hline hilippines & 1.998 & $(0.009)$ & 1.656 & $(0.021)$ & 1.505 & $(0.024)$ & 4.504 & $(0.078)$ \\
\hline eru & .413 & $(0.022)$ & 1.497 & $(0.044)$ & 1.424 & $(0.047)$ & 4.153 & $(0.113)$ \\
\hline Guyana & 1.666 & $(0.025)$ & 1.451 & $(0.060)$ & 1.403 & $(0.064)$ & 4.067 & $(0.145)$ \\
\hline maica & 238 & $(0.033)$ & 1.398 & $(0.056)$ & 1.332 & $0.060)$ & .790 & $(0.110)$ \\
\hline razil & 579 & $(0.017)$ & 1.362 & $(0.037)$ & 327 & $(0.042)$ & .769 & $(0.059)$ \\
\hline Ca & 372 & $(0.030)$ & 1.397 & $(0.059)$ & .293 & $(0.062)$ & 3.643 & $(0.152)$ \\
\hline anama & 1.429 & $(0.021)$ & 1.446 & $(0.056)$ & 1.291 & $(0.086)$ & 3.635 & $(0.123)$ \\
\hline Chile & 1.221 & $(0.027)$ & 1.324 & $(0.067)$ & 1.276 & $(0.084)$ & 3.582 & $(0.064)$ \\
\hline Guatemala & 1.536 & $(0.025)$ & 1.213 & $(0.078)$ & 1.171 & $(0.080)$ & 3.226 & $(0.107)$ \\
\hline Uruguay & 1.297 & $(0.041)$ & 1.191 & $(0.104)$ & 1.157 & $(0.130)$ & 3.181 & $(0.126)$ \\
\hline Colombia & 1.353 & $(0.013)$ & 1.195 & $(0.030)$ & 1.121 & $(0.034)$ & 3.068 & $(0.056)$ \\
\hline outh Africa & 1.389 & $(0.037)$ & 1.193 & $(0.090)$ & 1.094 & $(0.107)$ & 2.985 & $(0.121)$ \\
\hline Paraguay & 1.168 & $(0.074)$ & 1.016 & $(0.156)$ & 1.067 & $(0.179)$ & .907 & $(0.082)$ \\
\hline hailand & 1.335 & $(0$. & 1.2 & $(0.062)$ & 1. & $(0.08$ & 8 & $(0.129)$ \\
\hline urkey & 1246 & $(0.02$ & 1.122 & $(0.07$ & 10 & $(0$ & 5 & $(0.017)$ \\
\hline Belize & 1.250 & $(0.048)$ & 0.945 & $(0.129)$ & 0.968 & $(0.158)$ & 2.633 & $(0.247)$ \\
\hline Mexico & 1.001 & $(0.014)$ & 1.045 & $(0.034)$ & 0.951 & $(0.035)$ & 2.589 & $(0.025)$ \\
\hline Argentina & 1.057 & $(0.024)$ & 1.053 & $(0.067)$ & 0.911 & $(0.089)$ & 2.486 & $(0.160)$ \\
\hline Costa Rica & 0.963 & $(0.028)$ & 0.870 & $(0.074)$ & 0.786 & $(0.087)$ & 2.194 & $(0.061)$ \\
\hline Dominican Rep & 0.890 & $(0.016)$ & 0.758 & $(0.049)$ & 0.734 & $(0.051)$ & 2.084 & $(0.066)$ \\
\hline Morocco & 1.402 & $(0.041)$ & 0.881 & $(0.087)$ & 0.706 & $(0.105)$ & 2.026 & $(0.107)$ \\
\hline
\end{tabular}

Estimates with controls: males age 35-39, 9-12 years education. Standard errors in parentheses (robust for $\ln \hat{R}_{c}$, bootstrapped for $\hat{R}_{c}$ ). 
Table 2: Lower bounds on $R$ from coefficient stability test

\begin{tabular}{|c|c|c|c|c|c|c|}
\hline & $\left.R_{c}\right|_{\delta=0}$ & Bound & on $\left.R\right|_{\delta=1}$ & $\left.\delta\right|_{R=1}$ & $R_{u} / R_{c}$ & $\$$ gain \\
\hline & & $\Pi=1.3$ & $\Pi=2.0$ & & & \\
\hline Nigeria & 16.308 & $>15.764$ & $>14.565$ & 82.319 & 1.022 & $>16,611$ \\
\hline Yemen & 15.114 & $>16.368$ & $>19.713$ & -34.074 & 0.921 & $>23,475$ \\
\hline Haiti & 14.245 & $>4.874$ & $>0.861$ & 2.477 & 1.153 & $>4,742$ \\
\hline Egypt & 13.526 & $>12.116$ & $>9.372$ & 23.661 & 1.096 & $>16,766$ \\
\hline Cambodia & 9.139 & $>9.151$ & $>9.179$ & -1669.983 & 0.999 & $>21,352$ \\
\hline Vietnam & 8.395 & $>7.554$ & $>5.904$ & 20.152 & 1.079 & $>15,432$ \\
\hline Ghana & 8.160 & $>6.232$ & $>3.323$ & 7.789 & 1.165 & $>12,810$ \\
\hline India & 7.859 & $>5.930$ & $>3.074$ & 7.322 & 1.415 & $>14,317$ \\
\hline Sierra Leone & 7.608 & $>6.269$ & $>3.991$ & 10.484 & 1.098 & $>12,789$ \\
\hline Cameroon & 7.477 & $>6.287$ & $>4.196$ & 11.608 & 1.240 & $>14,860$ \\
\hline Pakistan & 7.433 & $>5.847$ & $>3.615$ & 8.358 & 1.361 & $>13,845$ \\
\hline Indonesia & 7.069 & $>6.191$ & $>4.545$ & 14.759 & 1.222 & $>14,903$ \\
\hline Nepal & 6.692 & $>5.286$ & $>3.048$ & 8.058 & 1.314 & $>9,244$ \\
\hline Sri Lanka & 6.657 & $>5.328$ & $>3.169$ & 8.514 & 1.343 & $>12,218$ \\
\hline Venezuela & 6.532 & $>5.778$ & $>4.339$ & 15.287 & 1.169 & $>14,995$ \\
\hline Jordan & 5.593 & $>5.012$ & $>3.882$ & 15.715 & 1.150 & $>14,406$ \\
\hline Bangladesh & 5.487 & $>5.077$ & $>4.236$ & 21.919 & 1.134 & $>14,170$ \\
\hline Ecuador & 5.368 & $>5.092$ & $>4.504$ & 31.920 & 1.067 & $>13,537$ \\
\hline Uganda & 5.286 & $>4.242$ & $>2.540$ & 7.572 & 1.413 & $>12,140$ \\
\hline Bolivia & 5.106 & $>4.890$ & $>4.421$ & 37.767 & 1.073 & $>14,697$ \\
\hline Ethiopia & 4.585 & $>3.240$ & $>2.091$ & 4.388 & 1.685 & $>9,247$ \\
\hline
\end{tabular}




\begin{tabular}{|c|c|c|c|c|c|c|}
\hline Philippines & 4.504 & $>3.475$ & $>1.897$ & 5.802 & 1.404 & $>9,980$ \\
\hline Peru & 4.153 & $>4.106$ & $>3.996$ & 122.911 & 1.024 & $>15,375$ \\
\hline Guyana & 4.067 & $>1.902$ & $>0.495$ & 1.846 & 1.249 & $>5,042$ \\
\hline Jamaica & 3.790 & $>3.788$ & $>3.784$ & 2681.692 & 1.001 & $>15,605$ \\
\hline Brazil & 3.769 & $>3.400$ & $>2.674$ & 12.887 & 1.255 & $>15,019$ \\
\hline Nicaragua & 3.643 & $>3.430$ & $>2.980$ & 21.439 & 1.095 & $>12,488$ \\
\hline Panama & 3.635 & $>3.451$ & $>3.058$ & 24.861 & 1.101 & $>13,668$ \\
\hline Chile & 3.582 & $>3.564$ & $>3.523$ & 258.013 & 1.012 & $>15,971$ \\
\hline Guatemala & 3.226 & $>2.617$ & $>1.607$ & 5.603 & 1.336 & $>9,347$ \\
\hline Uruguay & 3.181 & $>3.023$ & $>2.685$ & 22.757 & 1.134 & $>20,241$ \\
\hline Colombia & 3.068 & $>2.835$ & $>2.356$ & 14.151 & 1.207 & $>11,282$ \\
\hline South Africa & 2.985 & $>2.523$ & $>1.703$ & 6.495 & 1.504 & $>16,207$ \\
\hline Paraguay & 2.907 & $>2.752$ & $>2.421$ & 19.464 & 1.167 & $>16,561$ \\
\hline Thailand & 2.828 & $>2.396$ & $>1.628$ & 6.275 & 1.521 & $>8,920$ \\
\hline Turkey & 2.735 & $>1.949$ & $>1.043$ & 2.972 & 1.344 & $>7,128$ \\
\hline Belize & 2.633 & $>2.248$ & $>1.554$ & 6.120 & 1.337 & $>12,006$ \\
\hline Mexico & 2.589 & $>2.557$ & $>2.484$ & 76.853 & 1.034 & $>10,523$ \\
\hline Argentina & 2.486 & $>2.364$ & $>2.101$ & 18.042 & 1.177 & $>12,135$ \\
\hline Costa Rica & 2.194 & $>2.096$ & $>1.885$ & 17.234 & 1.178 & $>9,563$ \\
\hline Dominican Rep. & 2.084 & $>1.899$ & $>1.530$ & 7.916 & 1.258 & $>7,728$ \\
\hline Morocco & 2.026 & $>1.665$ & $>1.054$ & 3.600 & 1.894 & $>5,876$ \\
\hline
\end{tabular}

Lower bounds on dollar gain (col. 6) are PPP\$/year using $\left.R\right|_{\delta=1, \Pi=1.3}$ from col. 2. 
Table 3: Selection in the literature

\begin{tabular}{|c|c|c|c|c|}
\hline Migrant origin & $R_{u} / R_{c}$ & $R_{c} / R$ & $\delta$ & Source \\
\hline Micronesia $\rightarrow$ US & 0.71 & 1.36 & -0.90 & Akee et al. (2010) \\
\hline Tonga $\rightarrow \mathrm{NZ}$ & 1.38 & 1.33 & +0.89 & McKenzie et al. (2010) \\
\hline Poland $\rightarrow$ UK & - & 1.14 & - & Budnik (2009) \\
\hline US Blacks 1920s $\rightarrow$ North & 1.11 & 1.05 & 0.48 & Collins and Wanamaker (2014) \\
\hline Finland $\rightarrow$ Sweden & 0.86 & 1.04 & -0.24 & Rooth and Saarela (2007) \\
\hline Norway $1900 \rightarrow$ US & - & 1.04 & & Abramitzky et al. (2012) \\
\hline Lithuania $\rightarrow$ UK/Ireland & $<1$ & $\sim 1$ & $\sim 0$ & Elsner (2013, p. 545) \\
\hline Poland $\rightarrow$ UK & - & $\sim 1$ & $\sim 0$ & Dustmann et al. (2015, p. 535) \\
\hline Israel $\rightarrow$ US & $>1$ & $\sim 1$ & $\sim 0$ & Gould and Moav (2016) \\
\hline Mexico $\rightarrow$ US & 0.85 & 0.90 & +0.65 & Fernández-Huertas (2011) \\
\hline Mexico $\rightarrow$ US & 0.89 & 0.73 & +2.25 & Ambrosini and Peri (2012) \\
\hline Romania $\rightarrow$ US & 1.20 & - & - & Ambrosini et al. (2015) \\
\hline Nicaragua $\rightarrow$ US & 0.89 & - & - & Barham and Boucher (1998) \\
\hline Puerto Rico $\rightarrow$ US & 0.87 & - & - & Ramos (1992) \\
\hline Romania $\rightarrow$ Spain & 0.87 & - & - & Ambrosini et al. (2015) \\
\hline Poor countries $\rightarrow$ US & $>1$ & $>1$ & $<0.33$ & Hendricks and Schoellman (2018) \\
\hline Poorest countries $\rightarrow$ US & $>1$ & $>1$ & $\approx 1$ & Hendricks and Schoellman (2018) \\
\hline
\end{tabular}

The calculations based on each source are explained in the Online Appendix. 'Poor countries' in the source have $1 / 2$ to $1 / 16$ of U.S. GDP per capita, including 36 of the 42 countries studied in this paper. 'Poorest countries' have $<1 / 16$ of U.S. GDP per capita, including the other eight countries studied here. 
Figure 1: Relative returns to unobserved skill, U.S. versus foreign, against $R_{c}$

(a) 5-8 years of education

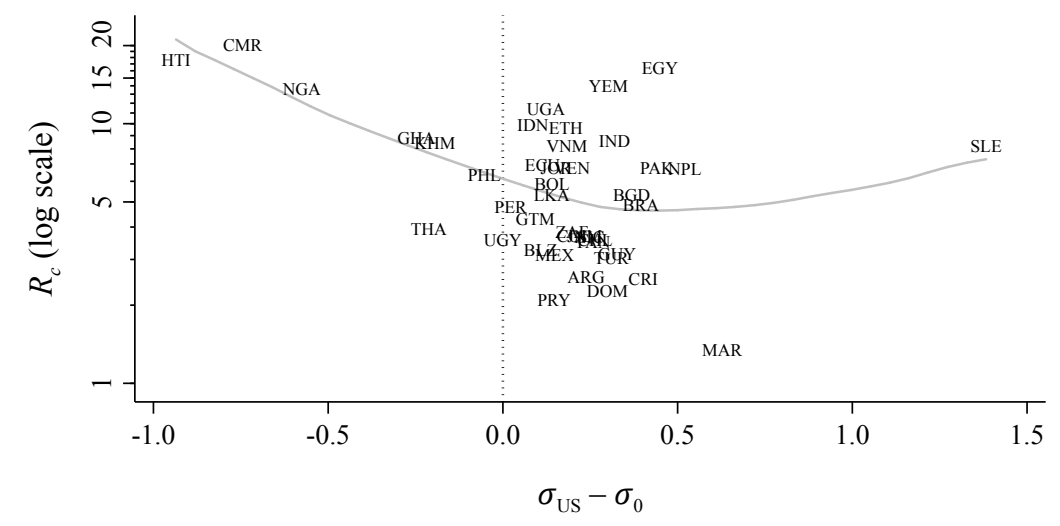

(b) 9-12 years of education



(c) $13+$ years of education

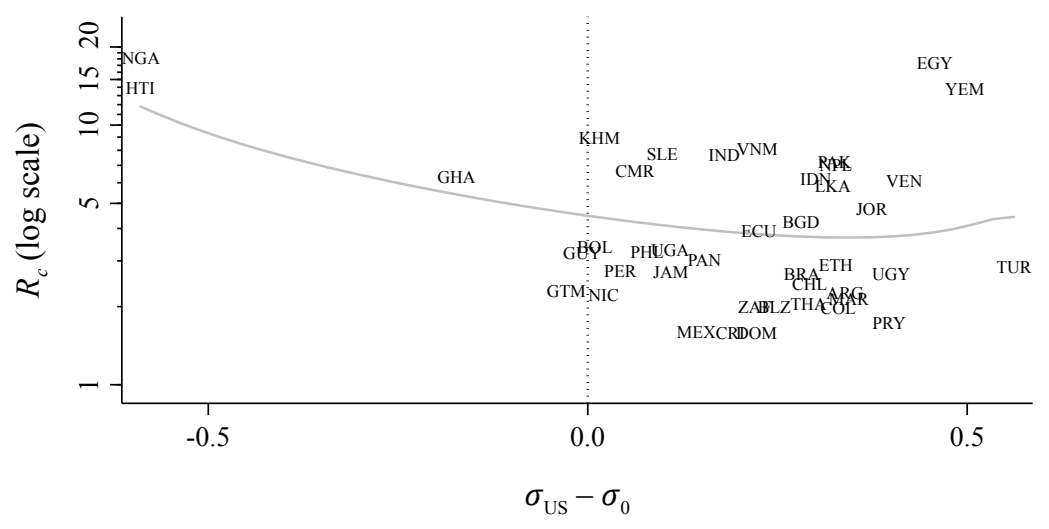

Gray line shows Fan local linear regression, Epanechnikov kernel, bandwidth 0.5. 
Figure 2: The degree of selection on observables against average wage at the origin, by observed skill

(a) 5-8 years of education

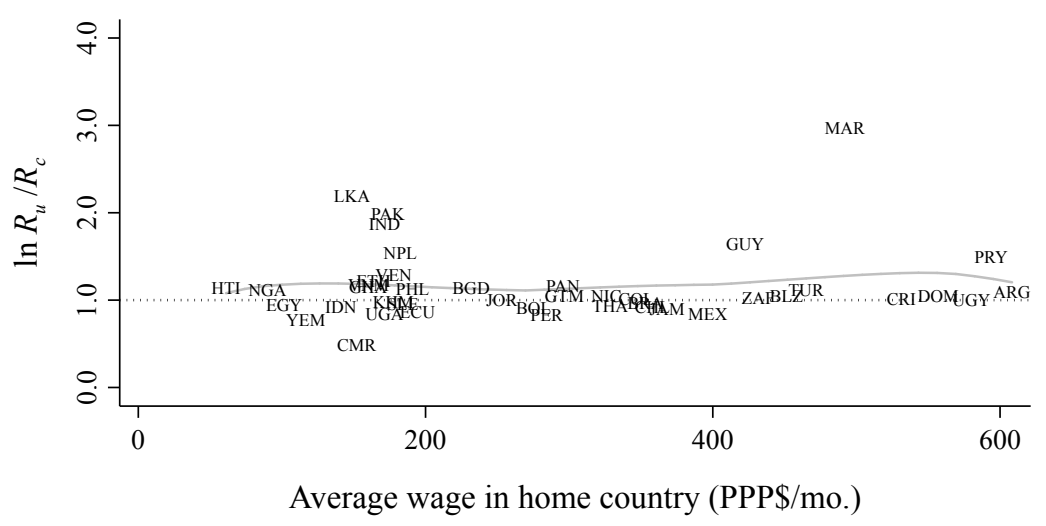

(b) 9-12 years of education

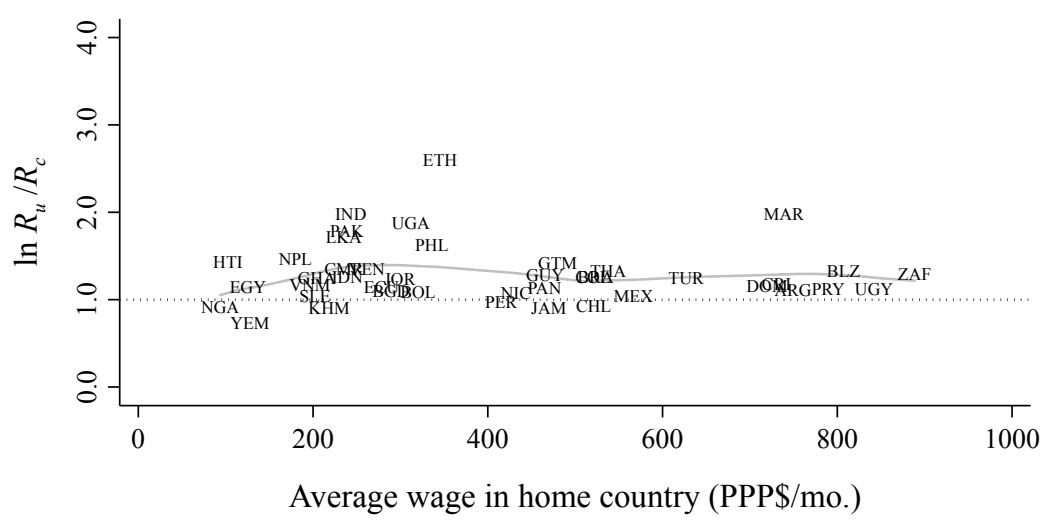

(c) $13+$ years of education

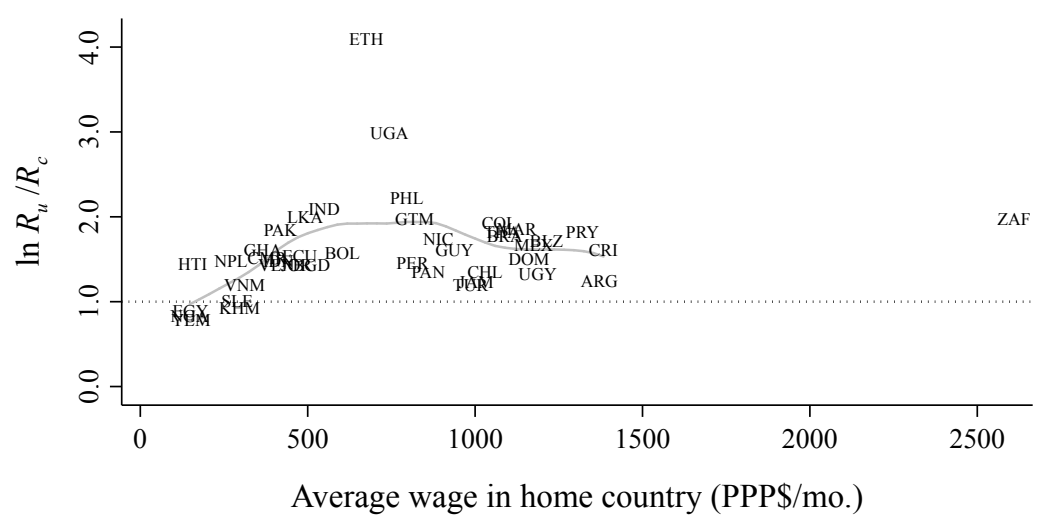

Gray line shows Fan local linear regression, Epanechnikov kernel, bandwidth 100 (panels a,b) or 175 (c). 
Figure 3: Relative wage of observably equivalent U.S. \& immigrant labor, vs. $R_{c}$

(a) 5-8 years of education



(b) 9-12 years of education

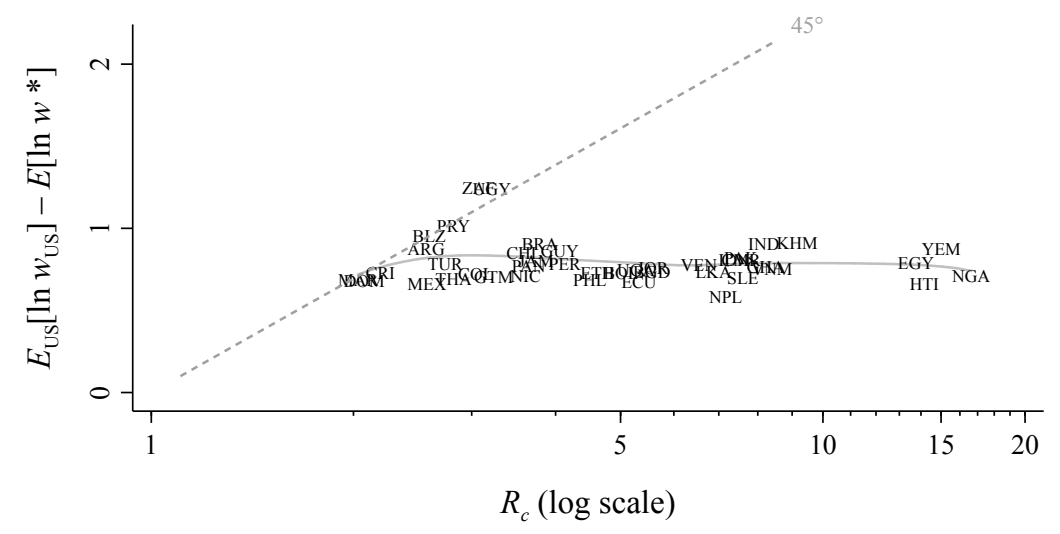

(c) $13+$ years of education

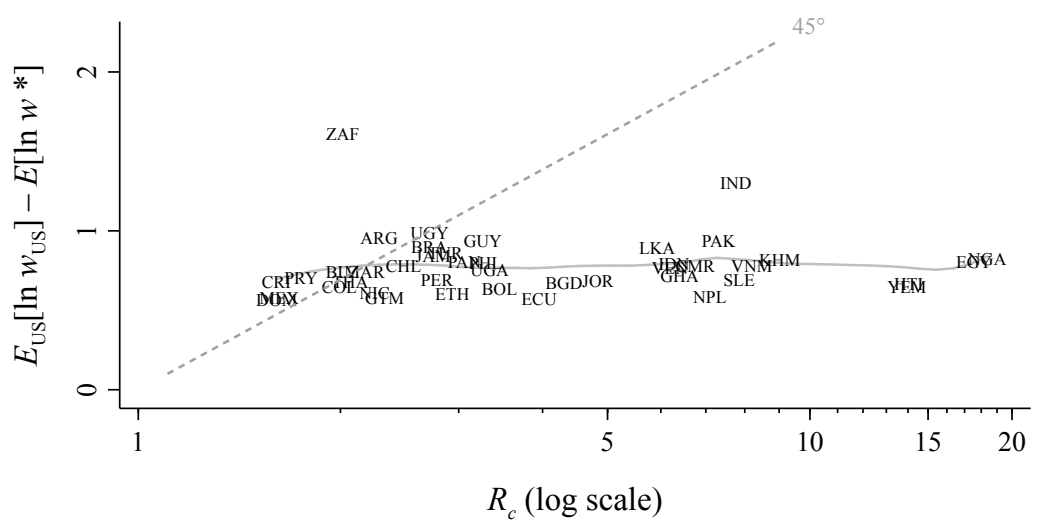

Gray line shows Fan local linear regression, Epanechnikov kernel, bandwidth 0.3 log points. 
Figure 4: Upper envelope of wages-forgone curve $\left(\bar{w}_{0}\right)$ by working-age population

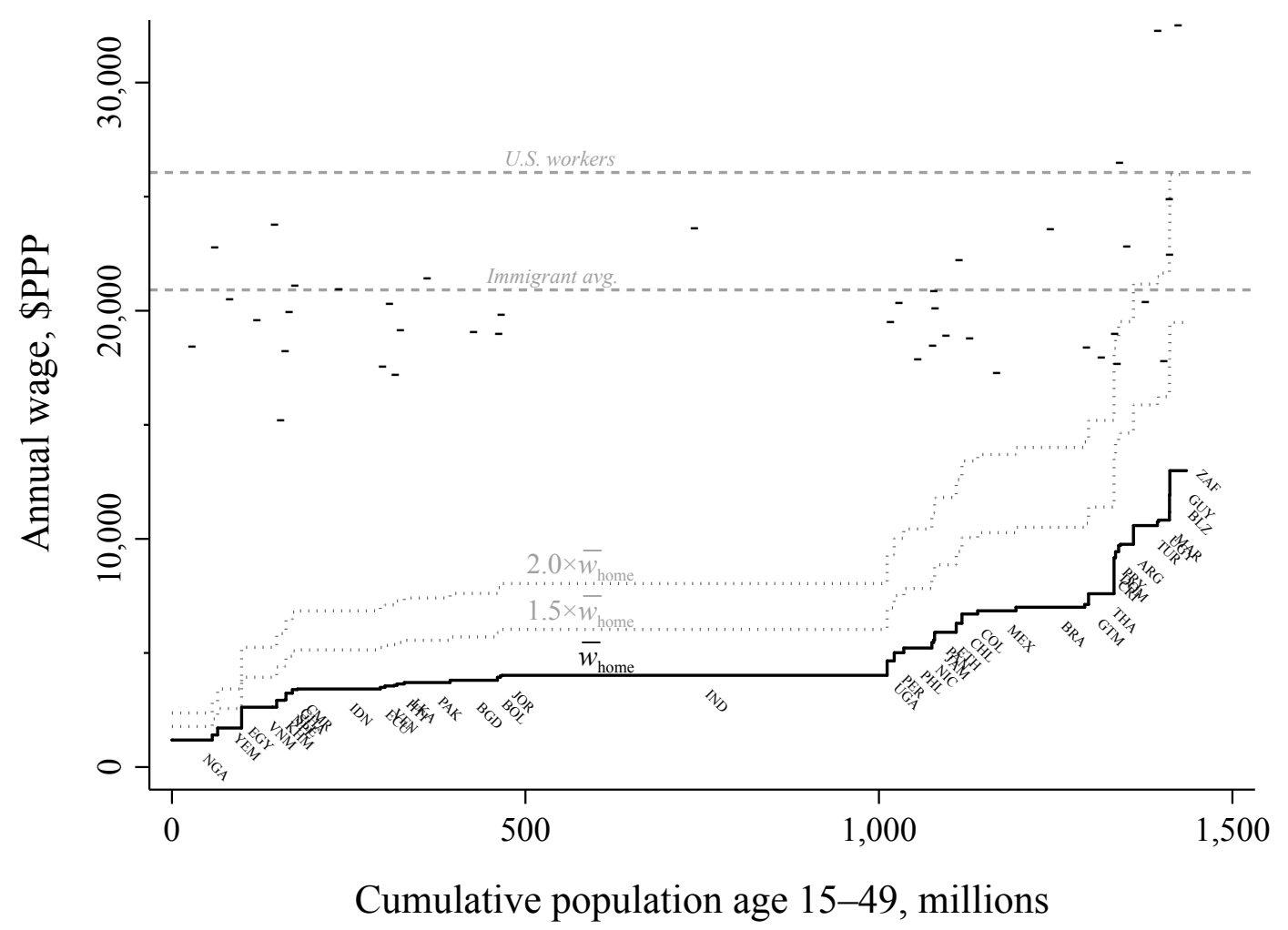

Note: For 35-39 year-old male workers with 9-12 years of schooling acquired in the home country. Upper envelope of wages forgone $\left(\bar{w}_{0}\right)$ estimated using lower bounds on $R$ from Table 2 col. 2: $\bar{w}_{0}=w_{\mathrm{US}} /\left.R\right|_{\delta=1, \Pi=1.3}$. Single dash is wage if immigrant in U.S., born and educated in each country specified directly below that dash. "Immigrant avg." is unweighted mean across country-of-birth for immigrants in U.S. "U.S. workers" is mean for U.S. born. 